\title{
Continued cognitive-behavior therapy versus sertraline for children and adolescents with obsessive-compulsive disorder that were non-responders to cognitive-behavior therapy: a randomized controlled trial
}

\author{
Gudmundur Skarphedinsson • Bernhard Weidle $\cdot$ Per Hove Thomsen • Kitty Dahl • \\ Nor Christian Torp • Judith B. Nissen - Karin Holmgren Melin • Katja Hybel • \\ Robert Valderhaug • Tore Wentzel-Larsen - Scott N. Compton • Tord Ivarsson
}

Received: 12 May 2014/Accepted: 27 August 2014/Published online: 20 September 2014

(C) The Author(s) 2014. This article is published with open access at Springerlink.com

\begin{abstract}
Expert guidelines recommend cognitivebehavior therapy (CBT) as a first-line treatment in pediatric obsessive-compulsive disorder (OCD) and the addition of selective serotonin reuptake inhibitors when CBT is not effective. However, the recommendations for CBT nonresponders are not supported by empirical data. Our objective was to investigate the effectiveness of sertraline (SRT) versus continued CBT in children and adolescents that did not respond to an initial course of CBT. Randomized controlled trial conducted in five sites in Denmark, Sweden and Norway, 54 children and adolescents, age 7-17 years, with DSM-IV primary OCD were randomized to SRT or continued CBT for 16 weeks. These participants had been classified as non-responders to CBT
\end{abstract}

G. Skarphedinsson $(\varangle) \cdot$ K. Dahl · N. C. Torp ·

$\mathrm{T}$. Wentzel-Larsen · T. Ivarsson

Center for Child and Adolescent Mental Health, Eastern and

Southern Norway, Gullhaugveien 1-3, 0484 Oslo, Norway

e-mail: gudmundr@gmail.com

B. Weidle $\cdot$ R. Valderhaug

Regional Center for Child and Youth Mental Health and Child

Welfare, Norwegian University of Science and Technology,

Klostergate 46, 7491 Trondheim, Norway

P. H. Thomsen - J. B. Nissen - K. Hybel

Research Department, Center for Child and Adolescent psychiatry, Aarhus University Hospital, Skovagervej 2, Indgang 81, 0824 Risskov, Denmark

K. H. Melin

Department of Child and Adolescent Psychiatry, BUP

Specialmottagning, Queen Silvia's Children's Hospital,

Sahlgrenska University Hospital, 41685 Gothenburg, Sweden

S. N. Compton

Duke University Medical Center, DUMC 3527, Durham,

NC 27710, USA following 14 weekly sessions. Primary outcomes were the CY-BOCS total score and clinical response (CY-BOCS $<16)$. The study was a part of the Nordic Long-Term OCD Treatment Study (NordLOTS). Intent-to-treat sample included 50 participants, mean age $14.0(\mathrm{SD}=2.7)$ and $48 \%(n=24)$ males. Twenty-one of 28 participants (75\%) completed continued CBT and 15 of 22 participants (69.2\%) completed SRT. Planned pairwise comparison of the CY-BOCS total score did not reveal a significant difference between the treatments $(p=.351)$, the response rate was $50.0 \%$ in the CBT group and $45.4 \%$ in the SRT group. The multivariate $\chi^{2}$ test suggested that there were no statistically significant differences between groups $(p=.727)$. Within-group effect sizes were large and significant across both treatments. These large within-group effect sizes suggest that continued treatment for CBT nonresponders is beneficial. However, there was no significant between-group differences in SRT or continued CBT at post-treatment.

Keywords Cognitive-behavior therapy $\cdot$ Selective serotonin reuptake inhibitors - Sertraline - Obsessivecompulsive disorder · Children and adolescents · Treatment outcome

\section{Introduction}

Obsessive-compulsive disorder (OCD) is a chronic and disabling disorder $[33,37,41]$ with a population prevalence rate between 1 and $3 \%[11,32,37,50]$. One-third to one half of adults with OCD report that the onset of their symptoms began in childhood [34]. OCD is associated with significant functional impairment [49] and ranked as the 10th leading worldwide cause of years lived with disability 
of all somatic or psychiatric disorders [25]. Since the 1980s, people with diagnosable OCD have been identified earlier and treatments for OCD have become increasingly effective [2, 13, 54]. These advancements will likely reduce the chronicity of OCD $[23,41,53]$ and its total economic cost to individuals and society.

Although current treatments for pediatric OCD are effective, not all patients experience sufficient benefit [2, 54]. In one of the largest randomized controlled trial (RCT) in pediatric OCD, the POTS Study [30], children and adolescents were randomized to four treatment conditions: cognitive behavioral therapy (CBT), sertraline (SRT), the combination of both (COMB), and pill placebo (PBO). After 12 weeks of acute treatment, clinical remission [defined as a Children's Yale-Brown Obsessive Compulsive Scale $($ CY-BOCS) of $<11$ ] was reported in 21,39 , and $54 \%$ of participants randomized to SRT, CBT, and $\mathrm{COMB}$, respectively [30]. While these results are encouraging, it also suggests that almost $50 \%$ of children and adolescents who receive evidence-based treatments will fail to show an adequate response. Moreover, follow-up studies of participants in randomized clinical trials suggest that $40 \%$ of children and adolescents with OCD will continue to meet diagnostic criteria for OCD 1-15 years following the end of acute treatment [23, 41] and an additional $20 \%$ will have clinically significant residual symptoms [41]. The development of interventions for treatment-refractory OCD is therefore critically important.

Current expert guidelines recommend CBT as the firstline treatment for children and adolescents with OCD [26]. If CBT is not sufficiently effective, medication augmentation [specifically, the selective serotonin reuptake inhibitors (SSRIs)] is recommended [1, 26]. However, the sequence of treatment implicit within these guidelines (namely, start with CBT and if the patient does not respond, then augment with an SSRI) is based on expert consensus, not empirical evidence. They also lack clinically useful details such as how many sessions of CBT should be provided before it is considered inadequate.

Although expert guidelines recommend medication augmentation when CBT is not effective, continued CBT without medication augmentation may also be a viable option. In most efficacy studies, CBT has been conducted for a limited period of time. The number of weekly CBT sessions commonly ranges between 10 and 16 [54]. It is not known if CBT response rates would be higher if more sessions were provided. It seems reasonable that CBT treatment of longer duration may increase response rates, particularly in severe cases in which more time may be needed before the benefit can be seen [18]. This question, however, has not been addressed by clinical researchers.

In clinical settings, clinicians often face the decision of whether to provide additional sessions of CBT for patients who show a partial response or recommend switching to an alternative treatment. Results from a randomized controlled trial (RCT) in adults with OCD suggest that switching to fluvoxamine over continued CBT in nonresponders may be more effective [51]. However, there are no similar empirical studies in pediatric populations. The question of whether medication is more effective than continued CBT in pediatric OCD remains unanswered.

This gap in the literature was one of the reasons that led to the Nordic Long-Term OCD Treatment Study (NordLOTS). NordLOTS is a multi-national, multi-step trial designed in part to evaluate the relative efficacy of continued CBT or switch to SRT among children and adolescents with OCD who were rated as non-responders to an initial course of individual CBT $[18,45]$. In NordLOTS, 269 children and adolescents with OCD were offered 14 sessions of weekly individual exposure-based CBT, as first step of clinical care (Step 1). Non-responders to Step 1 were then randomized to two alternative Step 2 treatments: (1) continued CBT or (2) SRT for additional 16 weeks (Step 2). All treatments were delivered in two specialized OCD clinics and 17 community treatment centers in three countries (Denmark, Norway, and Sweden). Clinical response, assessed at the end of Step 1 treatment by independent evaluators (IEs), was defined as a CY-BOCS total score $\leq 15$. Based on this criterion, $27.4 \%(n=66)$ of the original 269 participants in the NordLOTS study were determined to be non-responders to CBT [47] and eligible for Step 2 treatments. This article reports the results of Step 2 outcomes. Based on findings reported in [51], it was hypothesized that SRT would be superior to continued CBT in this population.

\section{Methods}

\section{Study design}

The rationale, design, and methods of the NordLOTS trial have been described in detail elsewhere [18, 45, 47]. A brief overview is provided here. NordLOTS included three main treatment steps. For Step 1, participants were recruited through referrals from community mental health centers, general practitioners, child mental health specialists or from parents/relatives who read information about the study trial on the internet. A total of 19 clinics in Denmark, Norway, and Sweden participated in the study within the following five main geographic areas: (1) Eastern and Southern Norway, (2) Central Norway, (3) Gothenburg, Sweden, (4) Stockholm, Sweden, and (5) Aarhus, Denmark. Participants included in Step 1 received 14 individual weekly treatment sessions of CBT. Experienced child and adolescent clinical psychologists, 
psychiatrists, or other specialized mental health professionals provided treatment. Therapists underwent 2 weeks of training in the NordLOTS treatment manual for pediatric OCD. To ensure understanding of the study and competent delivery of treatment, clinicians were required to treat at least two non-study patients under close supervision before being allowed to treat study participants. Clinicians received monthly group supervision within their respective sites.

Sessions were audiotaped and treatment fidelity for Step 1 was evaluated by an experienced CBT therapists involved in the project. Sessions were evaluated across three dimensions: (1) treatment adherence, (2) treatment competency, and (3) quality of the therapeutic relationship. Ninety-five percent of the audiotapes evaluated received a rating of "good" to "very good" [45]. Eleven child therapists in seven clinics provided continued CBT while eight child psychiatrists in five clinics provided the pharmacological treatment. The trial was approved by the Norwegian, Swedish and Danish Committees for Medical and Health Research Ethics and the Medical Products Agencies. The project was registered in Current Controlled Trials (www. controlled-trials.com ISRCTN66385119). The Center for Child and Adolescent Mental Health (RBUP), in Oslo, served as the coordinating center and the data management center. Informed consent was provided by parent(s) or guardian(s) and by children 11 years or older. No industry funding was provided. Funding was applied for at each national site so the total study received funding from national funders as well as some central funding. A list of all funding sources has been published elsewhere [45].

To randomize participants to Step 2 treatments, a blockwise stratified randomization procedure was applied. Gender and the presence of a tic disorder were used as stratification variables, as gender and tics have been shown to moderate treatment outcomes $[10,22]$. To ensure that randomization could not be predicted in advance, the randomization procedure was centralized at the coordinating center (RBUP) in Oslo.

\section{Study participants}

All NordLOTS Step 1 participants who were rated as CBT treatment non-responders $(\mathrm{CY}-\mathrm{BOCS} \geq 16$ ), and who were willing to accept one of the two randomized treatments (i.e., either continued CBT or SRT), were eligible to participate in NordLOTS Step 2. The cut-off CY-BOCS score was chosen as it represents participants with moderate or severe OCD. Due to ethical issues we wished to avoid treating participants with only mild OCD with sertraline. Being above this cut-off score includes the possibility of a treatment response in terms of major symptom reduction and does not necessarily reflect that participants did not respond to treatment in Step 1. The term "non-responder" was chosen for its convenience. However, we estimated the agreement between CY-BOCS $<16$ and $30 \%$ or more reduction on the CY-BOCS from baseline to week 13 . The kappa showed substantial agreement (0.75) as $7.1 \%$ $(n=17)$ had $30 \%$ or more reduction, but still had 16 points or more on the CY-BOCS. Likewise, only $2.2 \%$ $(n=6)$ participants had 15 or less points on the CY-BOCS without obtaining $30 \%$ or more reduction on the CYBOCS [47]. The inclusion and exclusion criteria of Step 1 and any additional criteria relevant to Step 2 are summarized below.

\section{Inclusion and exclusion criteria}

Children and adolescents, between the ages of 7 and 17 years at the beginning of Step 1, who were rated as nonresponders $(\mathrm{CY}-\mathrm{BOCS} \geq 16)$ at the end of Step 1 treatment and accepted randomization were eligible to participate in Step 2. The diagnosis of OCD [4] and the presence of comorbid disorders was confirmed at baseline assessment. To enhance generalizability and match the sample of children commonly seen in outpatient settings, children with psychiatric co-morbidities were allowed to participate in Step 1 and Step 2 as long as the comorbid disorder did not have a higher treatment priority (e.g., psychosis and severe depression). Exclusion criteria were by design kept to a minimum. Children in Step 1 (and therefore, Step 2) were excluded if they had an IQ below 70, could not speak or understand the language in the country where the study was conducted, had a psychiatric comorbidity that made participation in NordLOTS clinically inappropriate (for example, primary anorexia nervosa; anorexia in partial remission where OCD had become the residual and primary disorder was permitted), depression with suicidality that demanded treatment, psychosis, or autism spectrum disorders. However, PDD-NOS was allowed if symptoms of OCD were more impairing. Participants receiving treatment for OCD with either CBT or medication currently or within 6 months of the start of the study were also excluded. Two additional exclusion criteria were applied for participants in Step 2: (1) post-pubertal girls who were sexually active and who did not accept or tolerate adequate contraceptive methods were excluded and (2) post-pubertal girls with a positive pregnancy test.

\section{Measures}

The Schedule for Affective Disorders and Schizophrenia for School-Age Children Present and Lifetime Version (KSADS-PL) [19] was used for diagnostic assessments at baseline (Step 1. The Children's Yale-Brown Obsessive Compulsive Scale (CY-BOCS) [39] was used for assessment of scalar treatment response. The CY-BOCS is a 
clinician administered instrument that evaluates obsessions and compulsions separately on time consumed, distress, interference, resistance, and control. It yields separate severity scores for obsessions and compulsions (0-20) and a composite severity score (0-40). CY-BOCS assessments were completed at baseline, weeks 7 and 13 in Step 1 and weeks 22 and 30 in Step 2. The primary outcomes were the CY-BOCS total score and binary clinical response defined as $\mathrm{CY}$-BOCS $\leq 15$. A cut-off score of $\leq 15$ has been used in previous treatment studies for identifying treatment response, including a number of pharmacological studies $[14,35,44]$. Secondary outcomes were $30 \%$ or more reduction on the CY-BOCS from end of Step 1 treatment (week 13) to end of Step 2 treatment (week 30). Clinical remission was defined as week $30 \mathrm{CY}-\mathrm{BOCS} \leq 10$. CYBOCS interviews were videotaped or audiotaped, and inter-rater agreement (reliability) was assessed independently from a random sample of $12.8 \%$ of the interviews. The intra-class correlation coefficient for the CY-BOCS was 0.92 for the total score and 0.94 and 0.87 for obsessions and compulsions, respectively [47].

The Child Obsessive-Compulsive Impact Scale (COIS$\mathrm{R})$ is a 33-item self-report questionnaire designed to assess the impact of OCD symptoms on the psychosocial functioning of children and adolescent in home, social, and academic environments [29]. Each item is scored on a 4-point Likert scale $(0=$ not at all, $1=$ just a little, $2=$ pretty much, and $3=$ very much). Both parent and youth versions were used. Both versions have shown moderate to high internal consistency, for children $\alpha=0.78$ and parents $\alpha=0.92$ [29].

Adverse events (AEs) were carefully assessed in participants treated with SRT. AEs were defined as any harmful and undesired change in the child's condition since starting Step 2 treatment. Life-threatening events, hospitalization, disability or permanent damage were classified as serious adverse events (SAEs), in accordance with US Food and Drug Administration guidelines [48]. At Step 2 baseline and every visit thereafter the child and parent completed an AE checklist. The AE checklist was adapted from Kutcher [20]. The checklist was reviewed with the child and parent by the treating physician to determine frequency, severity, impairment, and any additional treatment. Any SAE was reported to the principal investigator (TI). Details of all the measures used in NordLOTS are described elsewhere [45].

Interventions

\section{Sertraline}

Sertraline treatment included 6 sessions over 16 weeks. Sertraline was chosen because it is the only approved SSRI for OCD treatment in children and adolescents in Denmark, Sweden and Norway [45] and it has shown to be equally effective as the other SSRIs [1]. The pharmacotherapy treatment manual was adapted from the manual used in the POTS study [30]. A starting dose of $25 \mathrm{mg}$ per day was titrated up to $100 \mathrm{mg}$ per day by week 4; children below 10 years of age with low weight could be started on a lower dose, if deemed necessary. If response was considered inadequate at a dose of $100 \mathrm{mg}$, the dose was increased gradually up to a maximum of $200 \mathrm{mg}$ per day by week 8 . Treatment response and AEs were monitored at every visit and the dose reduced if necessary. The manual also included guidelines for clinical support where participants were encouraged to practice exposure tasks learned during Step 1 treatment. However, introducing new exposure tasks was not allowed. The overall rationale for this component was to reduce the variability of non-specific treatment effects unrelated to SRT. Pharmacotherapists were required to use a standardized script and were instructed to (1) ask child and parent(s) about resistance to compulsions; (2) review activities the child will engage in once he or she improves; (3) whether the child actively uses treatment techniques learned during Step 1; (4) whether the child has engaged in exposures and the resulting outcome; (5) encourage the child to continue to do exposures and to not engage in avoidance or rituals; and (6) inquire and address any concerns the family has related to the medication.

\section{Continued CBT}

Participants randomized to continued CBT received 10 additional treatment sessions over 16 weeks. The same CBT principles used in Step 1 were used in Step 2. However, the therapist needed to conduct a new case formulation by identifying barriers that may have interfered with treatment received in Step 1. Common factors identified were: (1) the patient took long time to engage and start exposure exercises due to high levels of anxiety or low motivation; (2) family factors, such as high initial accommodation which made exposure homework difficult; (3) OCD appeared predominantly at home, school or other places and in-office exposures did not generate high enough anxiety levels to be helpful; (4) the participant's own expectation for improvement was low and less effort was exerted during exposure exercises; (5) a non-optimal relationship with the therapist may have interfered with treatment motivation. Based on these and other factors, the Step 2 CBT was tailored to address specific problems as deemed clinically appropriate by the treatment team. For instance, Step 1 participants whose onset of exposure exercises was delayed, for whatever the reason, were simply given more exposure exercises in Step 2 CBT. Or, for Step 1 participants whose OCD symptoms occurred 
primarily at home or at school, steps were taken to conduct in vivo exposures in the setting in which the symptoms most frequently occurred. Or, if certain family dynamics were seen as counter-productive, measures were taken to address these barriers. For instance, helping parents to not accommodate to their child's OCD, decreasing OCDrelated blame and guilt, or helping to generate developmentally appropriate patterns of family interactions. For these reasons, the Step 2 CBT was less manualized and more individually tailored to the needs of the participant while staying consistent with principles of good E/RP CBT. The format of sessions in Step 2 CBT was the same as in step 1 [47]. Sessions were scheduled for $90 \mathrm{~min}$, where the first hour centered on individual E/RP and the last half hour included family sessions with one or both parents. The family sessions were conducted in a similar manner as described by Piacentini and colleagues [28].

\section{Statistical analysis}

Of the 50 participants who entered Step 2 treatments, 14 (28\%) participants withdrew consent (seven in each treatment condition). However, all randomized participants who had a CY-BOCS total score of $\geq 16$ before Step 2 treatment started were included in the analyses according to intent-to-treat principles.

The statistical method employed was piecewise regression [38], sometimes referred to as a longitudinal discontinuity model [40]. This model, herein called the longitudinal discontinuity model, evaluates whether a shift in the outcome trajectory occurs following the occurrence of a known event. In this paper, the known event is the onset of Step 2 treatment. That is, the longitudinal discontinuity model was used to evaluate whether the introduction of sertraline in CBT non-responders would impact the symptom trajectory more than continuing CBT.

In order to evaluate longitudinal discontinuity models, a point in time along the trajectory is specified that marks the onset of when a given treatment was introduced. A significant change in slopes following the onset of Step 2 treatments suggests that the newer treatments are having an impact on the Step 2 outcomes above what would be expected if no treatment had been provided.

To address how sertraline could affect a participant's outcome trajectories, we conducted a standard multilevel model for change (or mixed effects linear regression) that included two random effects (intercept and days since baseline) and the following fixed effects: binary indicators for site ([grand mean centered] Aarhus, Southern and Eastern Norway, Central Norway, Stockholm), with Gothenburg serving as the reference category. To this basic model, a series of discontinuous multilevel models for change were fitted to the data using restricted maximum likelihood estimation. The outcome modeled (CY-BOCS total score; COIS-R) varied by the hypothesis under consideration and was evaluated by introducing to the "baseline" model a second level-1 individual growth trajectory with a discontinuity in both elevation and slope that marked the onset of Step 2 treatment: namely, sertraline. The variable TREATMENT, which was allowed to vary across subjects, was used to mark the onset of Step 2 treatments. This variable can be thought of as a new intercept for the second level-1 individual growth trajectory, and if found to be statistically significant, suggests that the addition of sertraline resulted in a shift (either up or down) in the average outcome trajectory. The variable POSTDAYS, also a time-varying predictor, marked the passage of time following receipt of sertraline. This variable, if found to be statistically significant, suggests that the average slope (i.e., rate of change) following receipt of sertraline was different than the slope during the period preceding the onset of Step 2 treatments. In other words, it captures the additive effect of sertraline on the outcome trajectory after receipt of a given treatment.

In addition, to evaluate whether the discontinuity varied across participants (i.e., the magnitude of the discontinuity was not the same for all participants), models in which DAYS and POSTDAYS were treated as random effects (in addition to fixed effects) were evaluated. To evaluate whether the addition of random effects for these two parameters resulted in a better fitting model, the change in the deviance statistics relative to the baseline model was used. This difference follows a Chi-square distribution with degrees of freedom equal to the difference in the number of parameters between the two models. In all models, residual error terms were assumed to follow a mean-zero, normal distribution with an unstructured covariance structure used to capture the within person correlation over time. Tests were two-tailed, and a $p$ value of less than .05 was considered statistically significant. Models were fit using PROC MIXED in SAS Statistical Software, Version 9.4 (SAS Institute, Cary, NC, USA).

Multivariate $\chi^{2}$ tests were conducted on the binary outcome following 16 weeks of Step 2 treatment. Multiple imputation was used to replace missing data. This was done with a sequential regression multivariate imputation algorithm [36]. The imputation model included all outcome measures, time in weeks, treatment indicators, stratification variables (sex and tic disorder) and all possible predictors and moderators. A total of 200 data sets were generated in accordance to recent guidelines $[6,16]$ in order to make both estimates, confidence intervals and $\mathrm{p}$ values reliable. Outcomes reported were calculated using Rubin's rules [36] for combining the results of the 200 identical analyses. This was done on each of the 200 imputed data sets and the 
results were combined and reported as an $F$ statistic. Tests were two-tailed, and a $p$ value of less than 0.05 was considered to indicate statistical significance. Multiple imputation was conducted by using the SAS macro IVEware [31], and computation of a combined $F$ statistic was conducted with the SAS macro COMBCHI [3].

We performed a power analysis on the adjusted posttreatment CY-BOCS total score which based on simulation in the multilevel models of each observation of the CYBOCS. Sample size was adequate to detect a moderate effect size $(d=0.50)$. We consider this to reflect a clinically significant treatment effect and correspond to a mean difference on the CY-BOCS of five points.

\section{Results}

\section{Recruitment and retention}

A total of 54 participants were randomized to SRT or continued CBT. Four participants assigned to SRT were re-evaluated using the CY-BOCS due to a treatment delay of more than 3 weeks. These four participants scored below 16 on the CY-BOCS reassessment and were therefore considered Step 1 treatment responders and not eligible for Step 2 treatment. Thus, they were not included in the Step 2 ITT sample. There were no significant differences between treatment condition in the percentage of participants who dropped out (i.e., withdrew consent) of the study, $\chi^{2}(1,49)=0.046, p=.830 \quad(\mathrm{CBT}=25 \%$; $\mathrm{SRT}=32 \%$ ). All SRT participants who dropped out did so because they were opposed to medication use for pediatric OCD. Six participants randomized to continued CBT did not wish to continue with CBT, while one participant terminated treatment because of somatic disease. For the remaining participants, treatment adherence for CBT was adequate, with $61.9 \%(n=13)$ of participating children showing "good" or "very good" levels of compliance and $95.2 \%(n=20)$ for CBT parents. In SRT, $53.3 \%(n=8)$ of participating children showed good or very good compliance and $90.5 \%(n=19)$ for SRT parents. The CONSORT flow diagram for the trial is shown in Fig. 1.

\section{Patient characteristics}

Step 2 participant characteristics and assessments are reported in Table 1. The mean CY-BOCS total score reduction in percentage from baseline to week 13 was 16.4 $(\mathrm{SD}=19.8)$. Sixteen participants $(32.0 \%)$ had elevated CY-BOCS scores or a reduction in the CY-BOCS of less than $10 \%$ from baseline to week 13 . Twenty-one $(42.0 \%)$ had a moderate reduction in the CY-BOCS of less than
$30 \%$ from baseline to week 13, while 13 (26.0 \%) showed $30-47 \%$ reduction in the CY-BOCS over this same period. No statistically significant difference was revealed between the groups $t(48)=-1.01, p=.317$. Step 1 CBT treatment adherence was adequate, as $48 \%(n=24)$ of the participating children showed "good" or "very good" levels of compliance and $76 \%(n=38)$ of the parents.

\section{Primary outcomes}

Planned pairwise comparison at week 30 showed that the difference between continued CBT and SRT was not statistically significant $t(119)=-0.94, \quad p=.351 \quad$ (See Table 2 and Fig. 2).

The binary CY-BOCS total score $($ CY-BOCS $<16)$ showed that $48.0 \%(n=24)$ of participants across both treatment conditions were rated as treatment responders at week 30 . In the continued CBT group, $50 \%(n=14)$ were deemed treatment responders at week 30 and $45.4 \%$ $(n=10)$ in the SRT group. The multivariate $\chi^{2}$ test suggested that there were no statistically significant differences between continued CBT and SRT in the proportion of treatment responders $(p=.727)$.

\section{Secondary outcomes}

On the parent COIS-R, planned pairwise comparison at week 30 showed that the difference between continued CBT and SRT was not statistically significant $(p=.660)$. However, on the child COIS-R, the SRT group had reported statistically significant lower scores when compared to the continued CBT group, $t(89)=-2.08$, $p=.040$ (see Table 2). A total of $40 \%$ of all participants showed $30 \%(n=20)$ or more reduction on the CYBOCS total score from week 13 to week 30 (Step 2 treatment period). In the continued CBT group, $35.7 \%$ $(n=10)$ showed a $30 \%$ or greater reduction on the CYBOCS total score from week 13 to week 30 , and $45.4 \%$ $(n=10)$ in the SRT group. The difference was not statistically significant $(p=0.476)$. A total of $30 \%(n=15)$ of all Step 2 participants had a CY-BOCS total score of 10 or below at post-treatment (week 30). In the continued CBT group, $32.1 \%(n=9)$ had CY-BOCS below 11 at week 30 assessment point and $27.2 \%(n=6)$ in the SRT group achieved a CY-BOCS total score of 10 or below. This difference was not statistically significant $(p=.676)$.

\section{Effect estimates}

The within-group effect size [24] for CY-BOCS total score was $1.19(95 \% \mathrm{CI}=0.54-1.83)$ for the SRT group and $1.04(95 \% \mathrm{CI}=0.47-1.61)$ for continued CBT. The effect size for the parent COIS-R was 0.45 (95\% CI $=-0.16$ to 
Fig. 1 CONSORT flow diagram of the NordLOTS Step 2

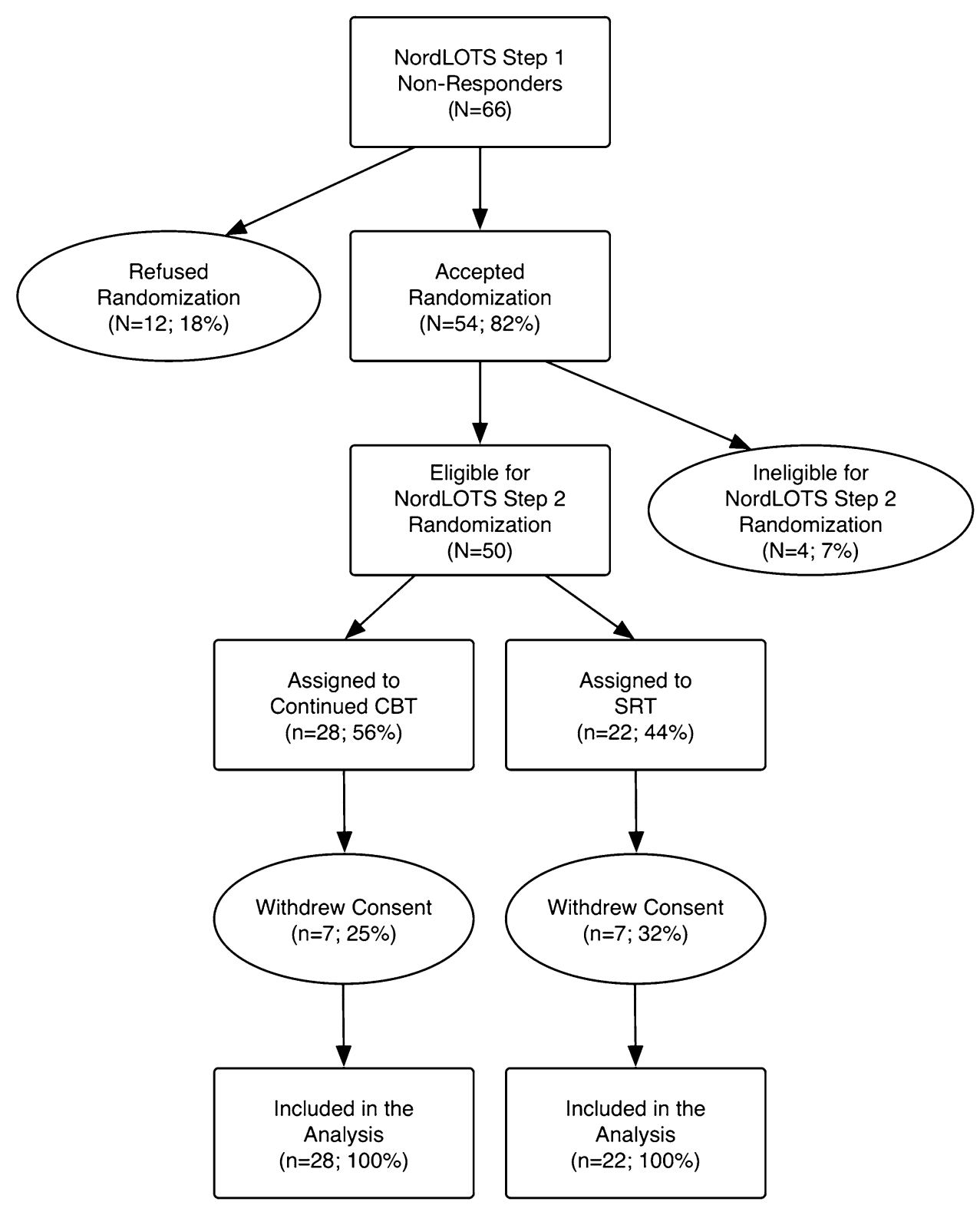

1.06) for the SRT group and 0.39 (95 \% CI $=-0.14$ to 0.92) for continued CBT. The effect size for the child COIS-R was $0.85(95 \% \mathrm{CI}=0.22-1.47)$ for the SRT group and 0.24 (95\% CI $=-0.29$ to 0.77$)$ for the continued CBT group.

\section{Adverse events}

A total of 12 of 15 SRT participants $(80.0 \%)$ reported at least one mild adverse event (AE) during the Step 2 treatment. AE outcomes are shown in Table 3. The most frequent AEs were gastrointestinal. Two participants reported mild increased suicidal ideation and one reported new onset mild suicidal thoughts. However, these events were attributed to current life stressor(s)/situation rather than the medication; and, hence, the participants did not discontinue their study medication. No SAEs were reported.

\section{Discussion}

The objective of the study was to compare sertraline with continued CBT for the treatment of pediatric OCD among a sample of children who had received an adequate trial of CBT (14 weeks of individual outpatient exposure-based CBT) and deemed to be CBT non-responders (CY-BOCS $\geq 16$ ).

RCTs of treatment-resistant pediatric OCD are extremely rare $[12,17]$, especially given the low prevalence of OCD and the success rate of first-line treatments [28, 30, 47]. This is the first RCT of CBT non-responders in 
Table 1 Baseline demographic and clinical characteristics by treatment group in NordLOTS Step 2

\begin{tabular}{|c|c|c|c|}
\hline Characteristics & $\begin{array}{l}\text { Sertraline } \\
(n=22)\end{array}$ & $\begin{array}{l}\text { CBT } \\
(n=28)\end{array}$ & $\begin{array}{l}\text { Total } \\
(n=50)\end{array}$ \\
\hline \multicolumn{4}{|l|}{ Sex $[$ No. $(\%)]$} \\
\hline Male & $11(50.0)$ & $13(46.4)$ & $24(48.0)$ \\
\hline Female & $11(50.0)$ & $15(53.6)$ & $26(52.0)$ \\
\hline Age [mean (SD) in years] & $14.1(2.8)$ & $14.0(2.8)$ & $14.0(2.7)$ \\
\hline \multicolumn{4}{|l|}{ Family status [No. (\%)] } \\
\hline $\begin{array}{l}\text { Biological parents } \\
\text { living together }\end{array}$ & $15(68.2)$ & $16(57.1)$ & $31(62.0)$ \\
\hline Divorced & $7(31.8)$ & $12(42.9)$ & $19(38.0)$ \\
\hline \multicolumn{4}{|l|}{ SES [No. $(\%)]$} \\
\hline High & $14(63.6)$ & $16(57.1)$ & $30(62.5)$ \\
\hline Low & $8(36.4)$ & $10(35.7)$ & $18(37.5)$ \\
\hline \multicolumn{4}{|l|}{ Ethnicity [No. (\%)] } \\
\hline $\begin{array}{l}\text { At least one } \\
\text { Scandinavian parent }\end{array}$ & $22(100)$ & $27(96.4)$ & $49(98.0)$ \\
\hline \multicolumn{4}{|l|}{ Scalar variables [mean $(\mathrm{SD})]$} \\
\hline $\begin{array}{l}\text { CY-BOCS total score } \\
\text { week } 0\end{array}$ & $25.2(5.0)$ & $27.3(5.9)$ & $26.4(5.6)$ \\
\hline $\begin{array}{l}\text { CY-BOCS total score } \\
\text { week } 13\end{array}$ & $21.1(3.7)$ & $21.3(4.0)$ & $21.3(3.8)$ \\
\hline CGAS week 0 & $52.8(10.3)$ & $52.3(6.4)$ & $52.5(8.2)$ \\
\hline CGAS week 13 & $58.1(10.5)$ & $58.6(8.2)$ & $58.4(9.2)$ \\
\hline \multicolumn{4}{|c|}{ Psychiatric comorbid disorders [No. $(\%)]$} \\
\hline $\begin{array}{l}\text { Any depressive } \\
\text { disorders }\end{array}$ & $0(0)$ & $3(10.7)$ & $3(6.0)$ \\
\hline Any anxiety disorders & $4(18.2)$ & $8(28.6)$ & $12(24.0)$ \\
\hline ADHD & $2(9.1)$ & $5(17.9)$ & $7(14.0)$ \\
\hline ODD and CD & $0(0)$ & $1(3.6)$ & $1(2.0)$ \\
\hline Tic disorders & $5(22.7)$ & $7(25.0)$ & $12(24.0)$ \\
\hline Any disorder & $7(31.8)$ & $17(60.7)$ & $23(46.0)$ \\
\hline
\end{tabular}

pediatric OCD to date. The study is not a direct comparison of CBT and SSRI in a sample of treatment naive children and adolescents. Rather, it is a comparison between CBT and SSRI among children and adolescents with OCD who failed to respond or benefit from an initial course of CBT.

Overall, there were no significant differences on the primary outcome measures between SRT and continued CBT among children who did not show an adequate response to an initial course of CBT. However, withingroup effect size estimates on the CY-BOCS total score were large for both continued CBT (1.04, $95 \%$ $\mathrm{CI}=0.47-1.61)$ and $\mathrm{SRT}(1.19,95 \% \mathrm{CI}=0.54-1.83)$ and the response rate across both groups was $48.0 \%$. The response rate in step 1 was $72.6 \%$ [47] and the combined Step 1 and Step 2 response rate was $81.4 \%$, indicating, that improvement can still be achieved with continued treatment. The rate of remitters (CY-BOCS <11) was $30.0 \%$ across groups in this trial. In step 1 it was $49.4 \%$ [47] and the combined Step 1 and Step 2 remittance rate was $55.0 \%$. Although the Step 1 remittance rate was already high (higher than reported in previous CBT trials $[28,30]$ ), response rates in children that initially received CBT continued to increase regardless of whether they continued CBT or switched to SSRI.

Analyses of the child COIS-R showed that the SRT group had significantly lower scores compared to the continued CBT group, while there were no significant differences on the parent COIS. Children in the SRT group reported less OCD-related functional impairment at posttreatment than the continued CBT group. The within-group effect size estimate for the SRT group was large $(0.85$, $95 \%$ CI 0.22-1.47) and statistically significant, while the within-group effect size estimate for the continued CBT group was small $(0.24,95 \% \mathrm{CI}-0.29$ to 0.77$)$ and nonsignificant. No clinically meaningful cut-off points have been developed for the COIS-R and the test-retest variability of the scale has not been established. However, the effect size estimate for the SRT group is similar to results reported in previous studies [28, 42].

The results of the primary outcome measures in the current study stand in contrast to the adult OCD study where fluvoxamine proved to be superior to cognitive therapy without E/RP [51]. In that study, participants randomized to CBT did not continue with E/RP in Step 2, but switched to cognitive therapy without E/RP which was limited to twelve 45-min sessions. Previous studies on adults with OCD have produced mixed results in terms of effectiveness of cognitive therapy without E/RP, some have not shown any difference $[8,52]$ and other have shown that E/RP is superior $[9,27]$. One speculation is that our continued individual exposure-based CBT may have produced more effect than the cognitive therapy used in the adult OCD study.

The CBT in Step 2 had the same format as Step 1 CBT. Sessions were scheduled for $90 \mathrm{~min}$, the first $60 \mathrm{~min}$ centered on individual E/RP while the last 30 min included family sessions with one or both parents. In spite of a reassessment and new case formulation prior to its initiation, step 2 CBT did not differ considerably from Step 1 CBT in frequency, intensity, format, etc. The large effect size of Step 2 CBT and additional response rate from Step 1 response indicates that children with OCD that do not respond to initial CBT may benefit by engaging in CBT for a longer period given that a new case formulation with identification of interference factors is implemented.

The side effect profile of sertraline in the current study was similar to those reported in other studies [21, 30]. It should be noted that no SAEs were reported. AEs of the participants randomized to continued CBT were not assessed, so it is not possible to compare differences 
Table 2 Post-treatment Group-specific mean and response rates

\begin{tabular}{|c|c|c|c|}
\hline & \multicolumn{2}{|c|}{ Estimated mean or rate $(95 \% \mathrm{CI})^{\mathrm{a}}$} & \multirow[t]{2}{*}{ Effect sizes CBT vs. SRT $(95 \% \text { CI })^{\text {b, c }}$} \\
\hline & Continued CBT & Sertraline & \\
\hline \multicolumn{4}{|l|}{ Primary outcomes } \\
\hline CY-BOCS total score ${ }^{\mathrm{d}}$ & $13.64(10.96-16.32)$ & $11.65(7.88-15.42)$ & $-0.29(-0.85$ to -0.27$)$ \\
\hline CY-BOCS $<16^{\mathrm{e}}$ & $0.50(0.33-0.67)$ & $0.45(0.27-0.65)$ & $0.10(-0.72$ to 0.52$)$ \\
\hline \multicolumn{4}{|l|}{ Secondary outcomes } \\
\hline COIS-R parent report ${ }^{\mathrm{f}}$ & $17.20(11.74-22.67)$ & $15.50(8.86-22.14)$ & $-0.11(-0.67$ to 0.45$)$ \\
\hline COIS-R child report ${ }^{\mathrm{f}}$ & $15.39(11.05-19.73)$ & $8.44(2.72-14.17)$ & $-0.55(-1.12$ to -0.02$)$ \\
\hline CY-BOCS $<11^{\mathrm{g}}$ & $0.32(0.18-0.51)$ & $0.27(0.13-0.48)$ & $-0.22(-0.41$ to 0.85$)$ \\
\hline $30 \%$ reduction $^{\mathrm{h}}$ & $0.36(0.21-0.54)$ & $0.45(0.27-0.65)$ & $0.13(-0.81$ to 0.55$)$ \\
\hline
\end{tabular}

${ }^{a}$ For CY-BOCS total score and COIS-R estimated mean score at week 30 from the fitted multilevel model. For the responder status, the estimated rate of response at week 30

${ }^{\mathrm{b}}$ For CY-BOCS total score and COIS-R, between-groups difference in estimated mean score at session 30. For the responder status, betweengroups difference in rate at week 30

${ }^{c}$ Negative effect size suggests that SRT was more effective and positive effect size suggests that continued CBT was more effective

${ }^{\mathrm{d}}$ CY-BOCS total score range from 0 to 40 with larger scores reflecting more OCD symptoms

e CY-BOCS $<16$ reflects participants that obtained CY-BOCS total score of 15 or below at week 30

${ }^{\mathrm{f}}$ COIS-R total score range from 0 to 99 with larger scores reflecting more OCD-related functional

g CY-BOCS $<11$ reflects participants that obtained CY-BOCS total score of 10 or below at week 30

h $30 \%$ reduction of CY-BOCS total score from week 13 to week 30

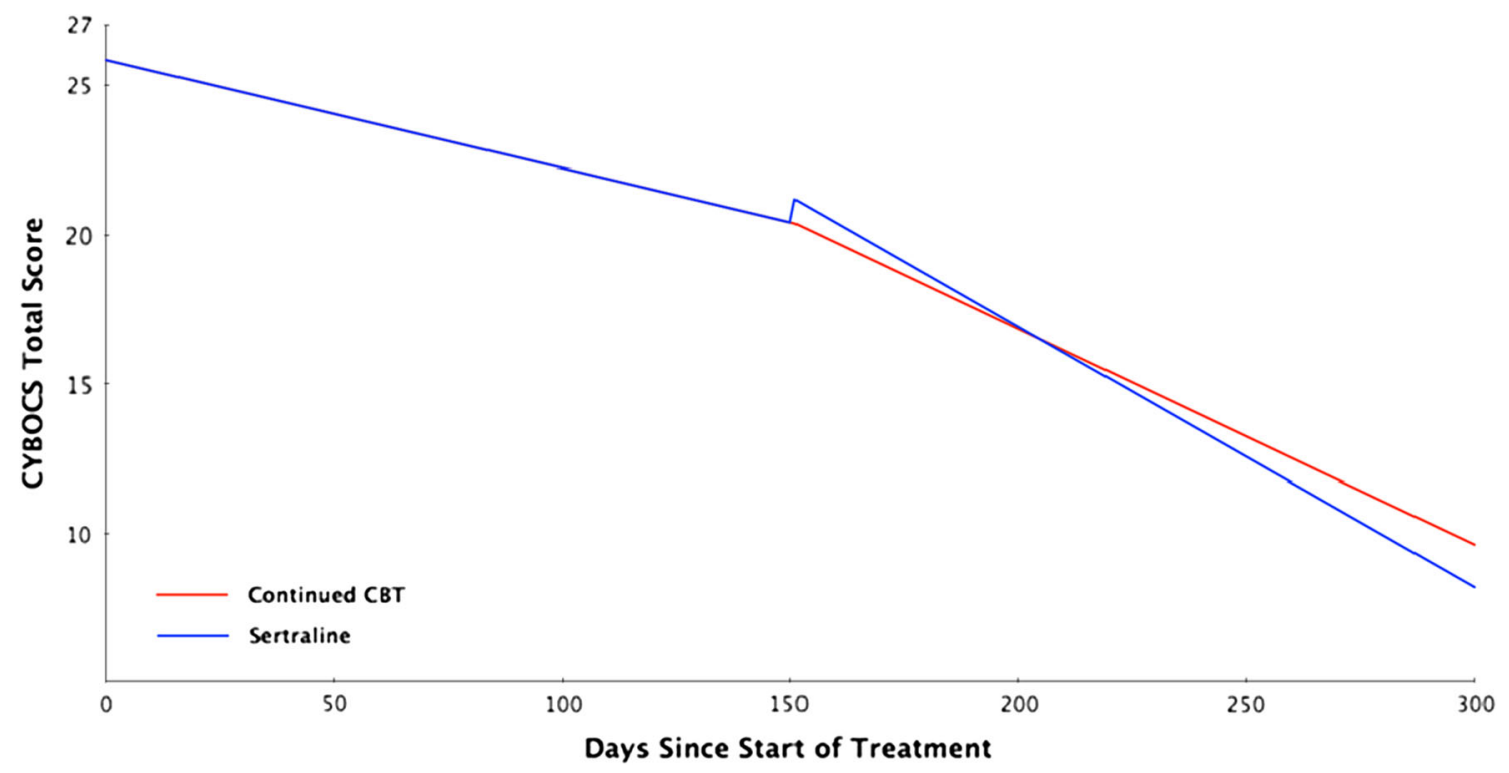

Fig. 2 Adjusted Intent-to-Treat CY-BOCS total score by days from baseline by treatment

between the two groups or estimate the base rate of AEs among participants who receive CBT. However, the results suggest that SRT is well tolerated as no participant needed to be prematurely terminated from treatment because of AEs. These findings mirror those reported in the literature for acute and 1-year outcomes [7, 53].

Results from the current analyses cannot be used to inform clinical decisions regarding which treatment (SRT or continued CBT) should be used following first-line CBT treatment. Current choices for a non-responding patient after 14 weeks would be: (1) to continue on CBT, optimally adjusted by a new case formulation or (2) switch to an SSRI. Other choices not evaluated in this study would be to combine CBT and SSRI. This choice is not strongly supported by empirical data. No studies exist on CBT nonresponders. The POTS study suggested the superiority of combined treatment (POTS, [30]). In contrast, a recent study by Storch and colleagues [42] did not find a 
Table 3 Adverse events in SSRI-treated participants

\begin{tabular}{lr}
\hline & $n(\%)$ \\
\hline Participants with AE $\geq 1$ & $12(80.0)$ \\
Gastrointestinal & $11(73.3)$ \\
Psychiatric other than suicidal & $9(60.0)$ \\
Suicidal thoughts or ideation & $3(20.0)$ \\
Sleep & $2(13.3)$ \\
Autonomic & $6(40.0)$ \\
Neurological & $5(33.3)$ \\
Menstruation & $1(6.7)$ \\
Sexual & $1(6.7)$ \\
Skin problems & $1(6.7)$ \\
\hline
\end{tabular}

significant differences between CBT and pill placebo versus CBT and sertraline. Another possibility for CBT nonresponders would be to adapt the CBT, for instance by intensifying it (increasing session length and session frequency). Two uncontrolled trials have reported promising results in treatment-resistant children and adolescents with OCD [5, 43].

\section{Strengths and limitations}

This is the first methodologically rigorous randomized controlled trial of CBT non-responders in pediatric OCD. A comprehensive standardized assessment battery has been employed, specifically trained and experienced independent evaluators and two active treatment comparisons were used.

Despite these strengths, there are limitations to the study. Although the severity of OCD continued to decrease in Step 2, it remains unclear how much of this decrease can be attributed to the treatments offered in Step 2 or to possible carry-over effects from Step 1. In this trial treatments were not compared to no treatment or placebo controls. Thus, the absolute effect of sertraline or continued CBT is not known. A future trial with a placebo control condition will be needed to rule out possible carry-over effects.

The attrition rate was fairly high, $28 \%$ across both treatment groups. All the SRT participants dropped out because parents did not wish medication as a treatment for OCD symptoms in their children while only one continued CBT participants did not want to continue CBT. The retention between steps seems to be a common problem in stepped care studies $[15,46]$.

\section{Conclusion}

Results did not show statistically significant differences between two treatment groups (continued CBT or SRT) among a sample of non-responders to CBT in pediatric OCD. However, within-group effect size estimate were large and significant across both treatments, suggesting that CBT non-responders are likely to benefit from either continued CBT or switching to an SSRI.

Acknowledgments The authors thank Dr. Martin E. Franklin, Dr. John Piacentini and Dr. John S. March for their role as international advisors. Dr. Martin E. Franklin receives a special gratitude for reading and commenting on the manuscript. The authors would also like to thank the patients and their parents that participated in the NordLOTS.

Open Access This article is distributed under the terms of the Creative Commons Attribution License which permits any use, distribution, and reproduction in any medium, provided the original author(s) and the source are credited.

\section{References}

1. AACAP (2012) Practice parameter for the assessment and treatment of children and adolescents with obsessive-compulsive disorder. J Am Acad Child Adolesc Psychiatry 51:98-113

2. Abramowitz J, Whiteside S, Deacon B (2005) The effectiveness of treatment for pediatric obsessive-compulsive disorder: a metaanalysis. Behav Ther 36:55-63

3. Allison PD. SAS Macros. http://www.statisticalhorizons.com/wpcontent/uploads/2012/01/combchi.sas (Updated December 17, 2007). Accessed 29 Jan 2014

4. American Psychiatric Association (2000) Diagnostic and Statistical Manual of Mental Disorders DSM-IV-TR Fourth Edition (Text Revision). American Psychiatric Association, Washington, DC

5. Bjorgvinsson T, Wetterneck CT, Powell DM, Chasson GS, Webb SA, Hart J, Heffelfinger S, Azzouz R, Entricht TL, Davidson JE, Stanley MA (2008) Treatment outcome for adolescent obsessivecompulsive disorder in a specialized hospital setting. J Psychiatric Pract 14:137-145

6. Carpenter J, Kenward M (2013) Multiple imputation and its application. Wiley, West Sussex

7. Cook EH, Wagner KD, March JS, Biederman J, Landau $\mathrm{P}$, Wolkow R, Messig M (2001) Long-term sertraline treatment of children and adolescents with obsessive-compulsive disorder. J Am Acad Child Adolesc Psychiatry 40:1175-1181

8. Cottraux J, Note I, Yao SN, Lafont S, Note B, Mollard E, Bouvard M, Sauteraud A, Bourgeois M, Dartigues JF (2001) A randomized controlled trial of cognitive therapy versus intensive behavior therapy in obsessive compulsive disorder. Psychother Psychosom 70:288-297

9. Fisher PL, Wells A (2005) How effective are cognitive and behavioral treatments for obsessive-compulsive disorder? A clinical significance analysis. Behav Res Ther 43:1543-1558

10. Flament MF, Rapoport JL, Berg CJ, Sceery W, Kilts C, Mellstrom B, Linnoila M (1985) Clomipramine treatment of childhood obsessive-compulsive disorder. A double-blind controlled study. Arch Gen Psychiatry 42:977-983

11. Flament MF, Whitaker A, Rapoport JL, Davies M, Berg CZ, Kalikow K, Sceery W, Shaffer D (1988) Obsessive compulsive disorder in adolescence: an epidemiological study. J Am Acad Child Adolesc Psychiatry 27:764-771

12. Franklin ME, Sapyta J, Freeman JB, Khanna M, Compton S, Almirall D, Moore P, Choate-Summers M, Garcia A, Edson AL, Foa EB, March JS (2011) Cognitive behavior therapy 
augmentation of pharmacotherapy in pediatric obsessive-compulsive disorder: the Pediatric OCD Treatment Study II (POTS II) randomized controlled trial. JAMA 306:1224-1232

13. Geller DA, Biederman J, Stewart SE, Mullin B, Martin A, Spencer T, Faraone SV (2003) Which SSRI? A meta-analysis of pharmacotherapy trials in pediatric obsessive-compulsive disorder. Am J Psychiatry 160:1919-1928

14. Geller DA, Hoog SL, Heiligenstein JH, Ricardi RK, Tamura R, Kluszynski S, Jacobson JG, Fluoxetine Pediatric OCD Study Team (2001) Fluoxetine treatment for obsessive-compulsive disorder in children and adolescents: a placebo-controlled clinical trial. J Am Acad Child Adolesc Psychiatry 40:773-779

15. Gilliam CM, Diefenbach GJ, Whiting SE, Tolin DF (2010) Stepped care for obsessive-compulsive disorder: an open trial. Behav Res Ther 48:1144-1149

16. Graham JW, Olchowski AE, Gilreath TD (2007) How many imputations are really needed? Some practical clarifications of multiple imputation theory. Prev Sci 8:206-213

17. Grant PJ, Joseph LA, Farmer CA, Luckenbaugh DA, Lougee LC, Zarate CA, Swedo SE (2014) 12-week placebo-controlled trial of add-on riluzole in the treatment of childhood-onset obsessive compulsive disorder. Neuropsychopharmacology 6:1453-1459

18. Ivarsson $\mathrm{T}$, Thomsen $\mathrm{PH}$, Dahl $\mathrm{K}$, Valderhaug R, Weidle B, Nissen JB, Englyst I, Christensen K, Torp NC, Melin K (2010) The rationale and some features of the Nordic Long-Term OCD Treatment Study (NordLOTS) in childhood and adolescence. Child Youth Care Forum 39:91-99

19. Kaufman J, Birmaher B, Brent D, Rao U, Flynn C, Moreci P, Williamson D, Ryan N (1997) Schedule for affective disorders and schizophrenia for school-age children-present and lifetime version (K-SADS-PL): initial reliability and validity data. J Am Acad Child Adolesc Psychiatry 36:980-988

20. Kutcher S (1997) Practitioner review: the pharmacotherapy of adolescent depression. J Child Psychol Psychiatry 38:755-767

21. March JS, Biederman J, Wolkow R, Safferman A, Mardekian J, Cook EH, Cutler NR, Dominguez R, Ferguson J, Muller B, Riesenberg R, Rosenthal M, Sallee FR, Wagner KD, Steiner H (1998) Sertraline in children and adolescents with obsessivecompulsive disorder: a multicenter randomized controlled trial. JAMA 280:1752-1756

22. March JS, Franklin ME, Leonard H, Garcia A, Moore P, Freeman J, Foa E (2007) Tics moderate treatment outcome with sertraline but not cognitive-behavior therapy in pediatric obsessive-compulsive disorder. Biol Psychiatry 61:344-347

23. Micali N, Heyman I, Perez M, Hilton K, Nakatani E, Turner C, Mataix-Cols D (2010) Long-term outcomes of obsessive-compulsive disorder: follow-up of 142 children and adolescents. Br J Psychiatry 197:128-134

24. Morris SB, DeShon RP (2002) Combining effect size estimates in meta-analysis with repeated measures and independent-groups designs. Psychol Methods 7:105-125

25. Murray CJL, López AD (eds) (1996) The global burden of disease: a comprehensive assessment of mortality and disability from diseases, injuries, and risk factors in 1990 and projected to 2020. Harvard University Press, Cambridge

26. National Institute for Heath and Clinical Excellence (2005) Obsessive compulsive disorder (OCD) and body dysmorphic disorder (BDD). In: Excellence NIfHaC (ed) National Institute for Health and Clinical Excellence, London, p National Institute for Health and Clinical Excellence

27. Olatunji BO, Rosenfield D, Tart CD, Cottraux J, Powers MB, Smits JA (2013) Behavioral versus cognitive treatment of obsessive-compulsive disorder: an examination of outcome and mediators of change. J Consult Clin Psychol 81:415-428

28. Piacentini J, Bergman RL, Chang S, Langley A, Peris T, Wood JJ, McCracken J (2011) Controlled comparison of family cognitive behavioral therapy and psychoeducation/relaxation training for child obsessive-compulsive disorder. J Am Acad Child Adolesc Psychiatry 50:1149-1161

29. Piacentini J, Peris TS, Bergman RL, Chang S, Jaffer M (2007) Functional impairment in childhood OCD: development and psychometrics properties of the Child Obsessive-Compulsive Impact Scale-Revised (COIS-R). J Clin Child Adolesc Psychol 36:645-653

30. POTS Study Team (2004) Cognitive-behavior therapy, sertraline, and their combination for children and adolescents with obsessive-compulsive disorder: the Pediatric OCD Treatment Study (POTS) randomized controlled trial. JAMA 292:1969-1976

31. Raghunathan TE, Lepkowski JM, Van Hoewyk J, Solenberger $P$ (2001) A multivariate technique for multiply imputing missing values using a sequence of regression models. Survey Methodol 27:85-96

32. Rapoport JL, Inoff-Germain G, Weissman MM, Greenwald S, Narrow WE, Jensen PS, Lahey BB, Canino G (2000) Childhood obsessive-compulsive disorder in the NIMH MECA study: parent versus child identification of cases. Methods for the Epidemiology of Child and Adolescent Mental Disorders. J Anxiety Disord 14:535-548

33. Rasmussen SA, Eisen JL (1992) The epidemiology and clinical features of obsessive compulsive disorder. Psychiatr Clin North Am 15:743-758

34. Rasmussen SA, Eisen JL (1990) Epidemiology of obsessive compulsive disorder. J Clin Psychiatry 51(Suppl):10-13 (discussion 14)

35. Riddle MA, Reeve EA, Yaryura-Tobias JA, Yang HM, Claghorn JL, Gaffney G, Greist JH, Holland D, McConville BJ, Pigott T, Walkup JT (2001) Fluvoxamine for children and adolescents with obsessive-compulsive disorder: a randomized, controlled, multicenter trial. J Am Acad Child Adolesc Psychiatry 40:222-229

36. Rubin DB (2004) Multiple imputation for nonresponse in surveys. Wiley Inter-Science, New York

37. Ruscio AM, Stein DJ, Chiu WT, Kessler RC (2010) The epidemiology of obsessive-compulsive disorder in the National Comorbidity Survey Replication. Mol Psychiatry 15:53-63

38. Ryan SE, Porth LS (2007) A tutorial on the piecewise regression approach applied to bedload transport data. General Technical Report RMRS-GTR-189. In: Department of Agriculture FS, Rocky Mountain Research Station (ed) Fort Collins, p 41

39. Scahill L, Riddle MA, McSwiggin-Hardin M, Ort SI, King RA, Goodman WK, Cicchetti D, Leckman JF (1997) Children's YaleBrown obsessive compulsive scale: reliability and validity. J Am Acad Child Adolesc Psychiatry 36:844-852

40. Singer JD, Willett JB (2003) Applied longitudinal data analysis: modeling change and event occurrence. Oxford University Press, Oxford

41. Stewart SE, Geller DA, Jenike M, Pauls D, Shaw D, Mullin B, Faraone SV (2004) Long-term outcome of pediatric obsessivecompulsive disorder: a meta-analysis and qualitative review of the literature. Acta Psychiatr Scand 110:4-13

42. Storch EA, Bussing R, Small BJ, Geffken GR, McNamara JP, Rahman O, Lewin AB, Garvan CS, Goodman WK, Murphy TK (2013) Randomized, placebo-controlled trial of cognitivebehavioral therapy alone or combined with sertraline in the treatment of pediatric obsessive-compulsive disorder. Behav Res Ther 51:823-829

43. Storch EA, Lehmkuhl HD, Ricketts E, Geffken GR, Marien W, Murphy TK (2010) An open trial of intensive family based cognitive-behavioral therapy in youth with obsessive-compulsive disorder who are medication partial responders or nonresponders. J Clin Child Adolesc Psychol 39:260-268

44. Storch EA, Lewin AB, De Nadai AS, Murphy TK (2010) Defining treatment response and remission in obsessive- 
compulsive disorder: a signal detection analysis of the Children's Yale-Brown Obsessive Compulsive Scale. J Am Acad Child Adolesc Psychiatry 49:708-717

45. Thomsen PH, Torp NC, Dahl K, Christensen K, Englyst I, Melin KH, Nissen JB, Hybel KA, Valderhaug R, Weidle B, Skarphedinsson G, von Bahr PL, Ivarsson T (2013) The Nordic long-term OCD treatment study (NordLOTS): rationale, design, and methods. Child Adolesc Psychiatry Mental Health (Electronic Resource) 7:41

46. Tolin DF, Diefenbach GJ, Gilliam CM (2011) Stepped care versus standard cognitive-behavioral therapy for obsessive-compulsive disorder: a preliminary study of efficacy and costs. Depress Anxiety 28:314-323

47. Torp NC, Dahl K, Skarphedinsson G, Thomsen P, Valderhaug R, Weidle B, Melin K, Hybel K, Lenhard F, Wentzel-Larsen T, Franklin M, Ivarsson T (2014) Effectiveness of cognitive behavior treatment for pediatric Obsessive-Compulsive Disorder: Acute outcomes from the Nordic Long-term OCD Treatment Study (NordLOTS). Manuscript submitted for publication

48. U.S. Food and Drug Administration (2012) What is a serious adverse event. In: U.S. Food and Drug Administration, Silver Spring

49. Valderhaug R, Ivarsson $\mathrm{T}$ (2005) Functional impairment in clinical samples of Norwegian and Swedish children and adolescents with obsessive-compulsive disorder. Eur Child Adolesc Psychiatry 14:164-173
50. Valleni-Basile LA, Garrison CZ, Jackson KL, Waller JL, McKeown RE, Addy CL, Cuffe SP (1994) Frequency of obsessive-compulsive disorder in a community sample of young adolescents. (Erratum appears in $\mathrm{J}$ Am Acad Child Adolesc Psychiatry. 1995 Feb, 34(2), pp 128-9; PMID: 7896644). J Am Acad Child Adolesc Psychiatry 33:782-791

51. van Balkom AJ, Emmelkamp PMG, Eikelenboom M, Hoogendoorn AW, Smit JH, van Oppen P (2012) Cognitive Therapy versus fluvoxamine as a second-step treatment in obsessivecompulsive disorder nonresponsive to first-step behavior therapy. Psychother Psychosom 81:366-374

52. van Oppen P, de Haan E, van Balkom AJ, Spinhoven P, Hoogduin K, van Dyck R (1995) Cognitive therapy and exposure in vivo in the treatment of obsessive compulsive disorder. Behav Res Ther 33:379-390

53. Wagner KD, Cook EH, Chung H, Messig M (2003) Remission status after long-term sertraline treatment of pediatric obsessivecompulsive disorder. J Child Adolesc Psychopharmacol 13(Suppl 1):S53-S60

54. Watson HJ, Rees CS (2008) Meta-analysis of randomized, controlled treatment trials for pediatric obsessive-compulsive disorder. J Child Psychol Psychiatry 49:489-498 